\title{
Prevalence and Aetiology of Heart Failure in Patients Seen at a Teaching Hospital in Ghana

\author{
Isaac Kofi Owusu ${ }^{1,2 *}$ and Yaw Adu-Boakye ${ }^{2}$
}

${ }^{1}$ Department of Medicine, School of Medical Sciences, College of Health Sciences, Kwame Nkrumah University of Science and Technology, Kumasi, Ghana ${ }^{2}$ Department of Medicine, Komfo Anokye Teaching Hospital, Kumasi, Ghana

\begin{abstract}
Heart failure is a major clinical problem worldwide. It has been recognized as a contributor to cardiovascular disease burden in Africa for many years. There are no data on the prevalence of heart failure in Ghana; and the prevalence of heart failure among patients attending out-patient clinics in Ghana is unknown. This study was designed to determine the prevalence and aetiology of heart failure among patients attending a cardiac clinic in the Department of Medicine, Komfo Anokye Teaching Hospital (KATH), Kumasi, Ghana. Medical records of 524 patients were selected from the cardiac clinic, using simple random sampling. The demographic, clinical, chest $X-r a y$, electrocardiographic and echocardiographic characteristics of the patients was examined. Among the 524 patients 398 of the patients had heart failure according to the modified Framingham criteria for the diagnosis of heart failure; giving rise to a prevalence of $76 \%$. The heart failure patients were aged between 13-97 years with the mean age ( \pm standard deviation) of $56.5( \pm 19)$ years. There were more females $(53.6 \% ; n=213)$ than males $(46.4 \% ; n=185)$. Majority (45\%) of the patients had New York Heart Association (NYHA) Functional class 2. The main aetiologies of heart failure were: hypertension $(45 \% ; n=179)$, rheumatic heart disease $(23 \% ; n=90)$, cardiomyopathy $(15 \%$; $n=58)$ Other emerging aetiologies of heart failure in Africa seen in these patients were degenerative valvular disease (7.6\%; $\mathrm{n}=31)$ and ischemic heart disease $(2.3 \% ; n=10)$.
\end{abstract}

Keywords: Heart failure; Hypertension; Prevalence; Rheumatic heart disease; Cardiomyopathy

\section{Introduction}

Heart failure is a chronic condition characterized by the inability of the heart to pump adequate blood to meet the demands of the body and/or doing so at increased filling pressures. It is a serious clinical condition which represents the end-stage of a myriad of other cardiac diseases.

Heart failure is a major clinical problem worldwide. It has been recognized as a contributor to cardiovascular disease burden in Africa for many years [1-4]. In internal medicine services in Africa, heart failure has been described as the fifth to sixth cause of hospital admission $[5,6]$.

Available data suggest that the aetiologies of heart failure in Africa differ from those seen in the Western world [7]. The most common underlying cause of heart failure in high-income countries is coronary artery disease [8]. In sub-Saharan Africa, the predominant causes are rheumatic heart disease, hypertensive heart disease and cardiomyopathy [9-11].

Heart failure has become a public health problem reaching epidemic levels especially for the elderly population. Data show that more than 20 million people have heart failure worldwide, and the prevalence of heart failure in developed countries is estimated as $2 \%$ [12]. The prevalence of heart failure has been shown to follow an exponential pattern, which rises with age and affects $6-10 \%$ of people over age 65 in developed countries [13-15].

Few epidemiologic data on the prevalence of heart failure are available in sub-Saharan Africa [16,17]. There are no data on the prevalence of heart failure in Ghana; and the prevalence of heart failure among patients attending out-patient clinics in Ghana is unknown. This study was therefore designed to determine the prevalence and aetiology of heart failure among patients attending a cardiac clinic in the Department of Medicine, Komfo Anokye Teaching Hospital (KATH), Kumasi, Ghana.

\section{Materials and Methods}

This was a descriptive study carried out at the cardiac clinic of Komfo Anokye Teaching Hospital (KATH), Kumasi, Ghana. Ethical approval was obtained from the appropriate ethical committee.

Medical records of 524 patients were selected from the cardiac clinic, using simple random sampling. The demographic, clinical, chest $\mathrm{X}$-ray, electrocardiographic and echocardiographic characteristics of the patients was examined. Heart failure was diagnosed, using the modified Framingham criteria for the diagnosis of heart failure $[10,18,19]$.

\section{Major criteria included}

Paroxysmal nocturnal dyspnoea, raised jugular venous pressure, clinical cardiomegaly, basal crepitations, S3 gallop, clinical acute pulmonary oedema, pulmonary upper lobe blood diversion on chest $\mathrm{X}$-ray or pulmonary oedema on chest X-ray.

\section{Minor criteria included}

Tachycardia, orthopnoea, exertional dyspnoea, nocturnal cough, hepatomegaly, pleural effusion, diuretic use.

Heart failure was diagnosed if the patient had two major and one minor or one major and two minor criteria.

*Corresponding author: Isaac Kofi Owusu, Department of Medicine, Schoo of Medical Sciences, College of Health Sciences, Kwame Nkrumah University of Science and Technology, Kumasi, Ghana, Tel: +233 2445657 02; E-mail: ikeowusu@yahoo.com

Received October 18, 2013; Accepted November 09, 2013; Published November 16, 2013

Citation: Owusu IK, Boakye YA (2013) Prevalence and Aetiology of Heart Failure in Patients Seen at a Teaching Hospital in Ghana. J Cardiovasc Dis Diagn 1: 131 doi:10.4172/2329-9517.1000131

Copyright: $\odot 2013$ Owusu IK, et al. This is an open-access article distributed under the terms of the Creative Commons Attribution License, which permits unrestricted use, distribution, and reproduction in any medium, provided the original author and source are credited. 
Hypertension was defined as the presence of a persistent elevated systolic blood pressure $\geq 140 \mathrm{mmHg}$ and/or diastolic blood pressure $\geq 90 \mathrm{mmHg}$ in patients aged 15 years and above and/or presence of hypertensive retinopathy and/or the use of antihypertensive drugs and/ or past medical history of hypertension $[20,21]$.

All the heart failure patients had standard transthoracic echocardiographic procedures performed by the author. The echocardiographic data of the patients which were obtained included; $\mathrm{m}$-mode, 2- dimensional, doppler, colour flow imaging, and valvular apparatus characteristics.

Left ventricular systolic dysfunction was defined as left ventricular ejection fraction $(\mathrm{EF})<50 \%$.

Left ventricular diastolic dysfunction was defined as E/A ratio $<1$ or $\mathrm{E} / \mathrm{A}$ ratio $>2, \mathrm{DT}>220 \mathrm{~ms}$ or $\mathrm{DT}<160 \mathrm{~ms}$, IVRT $>100 \mathrm{~ms}$ or IVRT $<70 \mathrm{~ms}$. Tissue Doppler imaging could not be done. Pulmonary hypertension was defined as right ventricular systolic pressure $\geq 35$ $\mathrm{mmHg}$ in the absence of pulmonary stenosis.

\section{Statistical analysis}

Data from the patients' medical records were entered into a Microsoft Excel (2010) sheet. Data were cleaned and abnormal variable and wrong entry removed or changed. Data were then exported into SPSS 12.0 software for analysis. Descriptive analysis of baseline parameters was provided. Measure of central tendency using mean was calculated, and measure of spread using standard deviation and range were also calculated.

\section{Results}

Among the 524 patients, 398 of the patients had heart failure according to the modified Framingham criteria for the diagnosis of heart failure; giving rise to a prevalence of $76 \%$. The heart failure patients were aged between 13-97 years with the mean age ( \pm standard deviation) of $56.5( \pm 19)$ years. There were more females $(53.6 \%$; $\mathrm{n}=213)$ than males $(46.4 \%, \mathrm{n}=185)$. Figure 1 shows age distribution of the heart failure patients.

Figure 2 shows the New York Heart Association (NYHA) Functional classification. The majority of the patients had NYHA functional class 2 , and $2.8 \%$ of the patients had asymptomatic heart failure.

Table 1 shows the echocardiographic characteristics of the heart failure patients. The mean left ventricular ejection fraction was $41.6 \%$. Left ventricular diastolic dysfunction with normal systolic function was seen in $24 \%(n=95)$ of the patients whilst left ventricular systolic dysfunction with or without a diastolic dysfunction occurred in $76 \%$ $(n=303)$ of the patients.

IVS-interventricular septum, LVPW-left ventricular posterior wall, LVIDd-left ventricular internal diameter in diastole, LVIDs-left ventricular internal diameter in systole, EF-left ventricular ejection fraction, FS-left ventricular fractional shortening, RVSP-right ventricular systolic pressure.

Table 2 shows the aetiology of heart failure. The main aetiologies of heart failure were: hypertension $(45 \% ; n=179)$, rheumatic heart disease $(23 \% ; n=90)$ and cardiomyopathy $(15 \% ; n=58)$. Other aetiologies of

Histogram

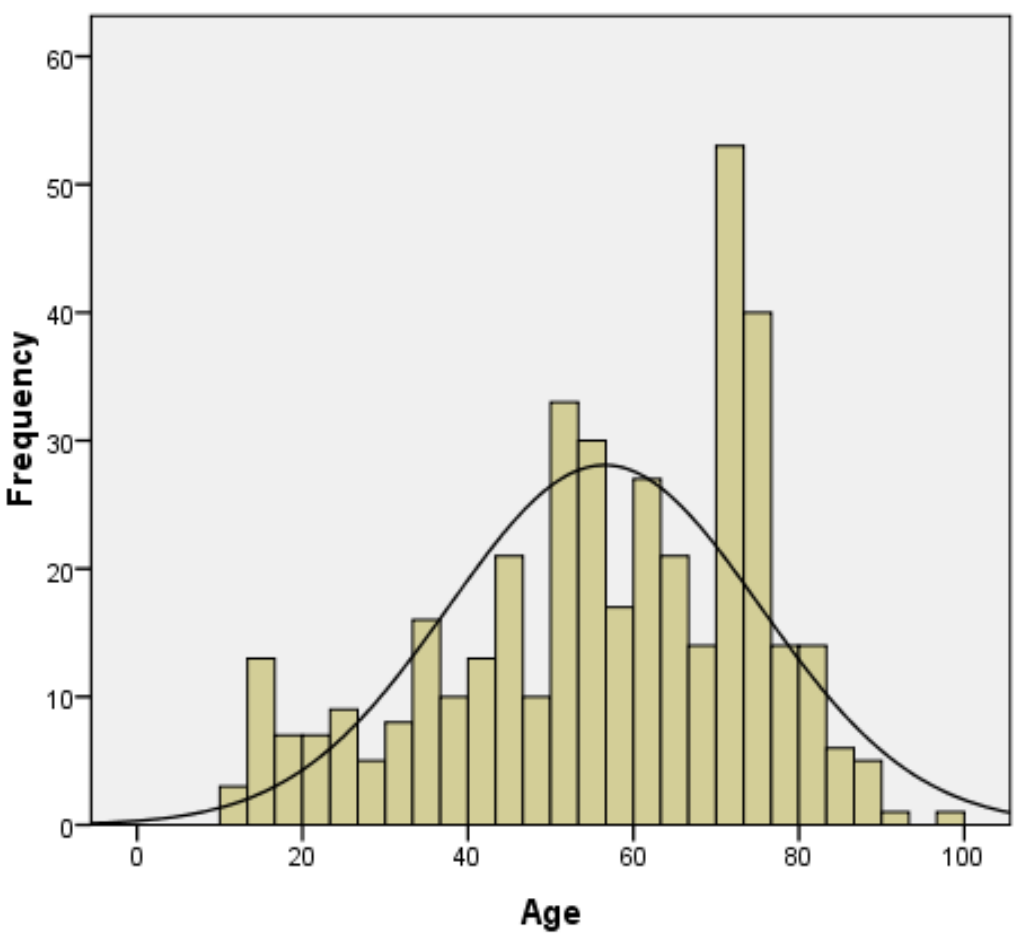

Mean $=56.51$
Std. Dev $=18.84$

$\mathrm{N}=398$

Figure 1: Histogram showing age distribution of heart failure patients. 


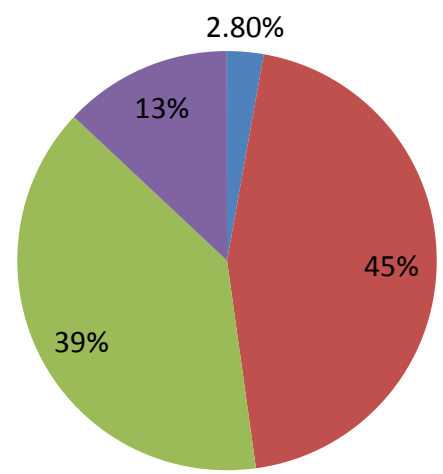

Figure 2: Pie Chart showing New York Heart Association Functional Classification of the heart failure patients.

\begin{tabular}{|c|c|c|c|}
\hline $\begin{array}{l}\text { Echocardiographic } \\
\text { characteristics }\end{array}$ & Mean & Standard Deviation & Range \\
\hline Aortic Root (cm) & 3.27 & 0.5 & $2-5$ \\
\hline Left Atrium (cm) & 3.94 & 0.9 & $2.1-7.6$ \\
\hline IVS (cm) & 1.2 & 0.3 & $0.6-2.8$ \\
\hline LVPW (cm) & 1.23 & 0.3 & $0.6-2.4$ \\
\hline LVIDd (cm) & 5.00 & 8.9 & $2.4-8.8$ \\
\hline LVIDs (cm) & 3.44 & 18 & $1.9-7.8$ \\
\hline FS (\%) & 21 & 12.7 & $2.6-41$ \\
\hline EF (\%) & 41.6 & 25 & $5-77$ \\
\hline $\mathrm{RVSP}(\mathrm{mmHg})$ & 55.7 & 17 & $30-120$ \\
\hline & \multicolumn{3}{|c|}{$\underline{\%}$} \\
\hline $\begin{array}{l}\text { Pulmonary } \\
\text { Hypertension }\end{array}$ & 120 & \multicolumn{2}{|c|}{30} \\
\hline LV Diastolic Dysfunction & 95 & \multicolumn{2}{|c|}{24} \\
\hline Dysfunction & 303 & \multicolumn{2}{|c|}{76} \\
\hline
\end{tabular}

Table 1: Echocardiographic characteristics of the heart failure patients.

\begin{tabular}{|c|c|c|}
\hline Aetiology of heart Failure & Number & Percentage \\
\hline Hypertension & 179 & $45 \%$ \\
\hline Rheumatic heart disease & 90 & $23 \%$ \\
\hline Cardiomyopathy & 58 & $15 \%$ \\
\hline Degenerative Valvular disease & 31 & $7.6 \%$ \\
\hline Ischaemic heart disease & 10 & $2.3 \%$ \\
\hline Pericardial disease & 9 & $2.2 \%$ \\
\hline Congenital heart disease & 7 & $1.7 \%$ \\
\hline Cor-pulmonale & 5 & $1.2 \%$ \\
\hline Others & 9 & $2.2 \%$ \\
\hline Total & 398 & $100 \%$ \\
\hline
\end{tabular}

Table 2 shows the aetiology of heart failure. The main aetiologies of heart failure were: hypertension $(45 \% ; n=179)$, rheumatic heart disease $(23 \% ; n=90)$ and cardiomyopathy $(15 \% ; n=58)$. Other aetiologies of heart failure seen in these patients were degenerative valvular disease $(7.6 \% ; n=31)$ and ischaemic heart disease $(2.3 \% ; n=10)$

Table 2: Aetiology of heart failure.

heart failure seen in these patients were degenerative valvular disease $(7.6 \% ; \mathrm{n}=31)$ and ischaemic heart disease $(2.3 \% ; \mathrm{n}=10)$.

\section{Discussion}

The high prevalence of heart failure of $76 \%$ seen in this study supports the fact that heart failure is a major contributor to cardiovascular disease burden in sub-Saharan Africa. Similar findings have been reported from Cameroun where heart failure is found to be the fifth to sixth cause of hospital admissions [5,6]. In other parts of sub-Saharan Africa, heart failure has been found to account to $5 \%$ to $10 \%$ of hospital admissions $[16,17,22,23]$. Some authors have also shown that heart failure is a major cause of cardiovascular disorder in Africa [24,25]. Heart failure is a major clinical problem worldwide. In the United States of America, prevalence of heart failure among African Americans between the ages of 45 to 65 was found to be about 70\% [26]. Another aspect of concern is the prevalence of asymptomatic heart failure. In Nigeria, Ogah et al. found the prevalence of asymptomatic heart failure among hypertensive patients at $18.1 \%$ [27]. Other studies have also found similar prevalence of asymptomatic heart failure [28, 29]. This is worrying and efforts should be made to reduce the high prevalence of heart failure through early detection of patients with cardiovascular risk factors and early introduction of neuro-hormonal blockers such as angiotensin converting enzyme inhibitors or angiotensin receptor blockers which may retard or prevent the development of heart failure.

The mean age of the heart failure patients was $56.5( \pm 19)$ years. This is in line with what was found in previous study in Kumasi, Ghana and other parts of sub-Saharan Africa [3-6,10]. Compared to the western world, heart failure in sub-Saharan African tends to occur at a much younger age. This finding could be due to the major contribution of rheumatic heart disease as a cause of heart failure in sub-Saharan Africa.

This study supports available data which show that rheumatic heart disease, hypertensive heart disease and cardiomyopathy are the main contributors to the aetiology of heart failure in Africa, accounting for over $80 \%$ of cases [9-11,24,30]. Rheumatic heart disease and hypertensive heart disease are largely preventable causes of heart failure. Hypertension has now become a public health problem in Africa. Studies have estimated prevalence of hypertension in various parts of Africa at $30 \%$ to $60 \%$ [31-34]. A study in Kenya showed that newly diagnosed rheumatic heart disease was found in $41 \%$ of heart failure patients referred for echocardiography [35]. Lack of access to surgery in Africa makes the prognosis of rheumatic heart disease worse; and majority of patients die at a younger age without surgical valve repair or replacement [36].

Our data have also shown that degenerative valvular disease and ischaemic heart disease are emerging as causes of heart failure in Africa. The prevalence of cardiovascular risk factors in Africa has been shown to be high by recent data [37-39]. Therefore, it is more likely that ischaemic heart disease is under-diagnosed in Africa, due to largely unavailability of coronary angiography and other imaging procedures.

\section{Conclusion}

Our data show high prevalence of heart failure among patients attending cardiac clinic in Kumasi, Ghana. Hypertension, rheumatic heart disease and cardiomyopathy were the main aetiologies of heart failure in these patients. Degenerative heart disease and ischemic heart disease are now emerging as causes of heart failure in Ghana.

\section{Acknowledgement}

The authors would like to express their sincere gratitude to the staff at the cardiac clinic of the Komfo Anokye Teaching Hospital, Kumasi, Ghana for their support. Without their co-operation this study would not have been done.

\section{References}

1. Ladipo GO, Froude JR, Parry EH (1977) Pattern of heart disease in adults of the Nigerian Savanna: a prospective clinical study. Afr J Med Med Sci 6 : 185-192.

2. Antony KK (1980) Pattern of cardiac failure in Northern Savanna Nigeria. Trop Geogr Med 32: 118-125. 
Citation: Owusu IK, Boakye YA (2013) Prevalence and Aetiology of Heart Failure in Patients Seen at a Teaching Hospital in Ghana. J Cardiovasc Dis Diagn 1: 131. doi:10.4172/2329-9517.1000131

3. Toure IA Salissou O, Chapko MK (1992) Hospitalizations in Niger (West Africa) for complications from arterial hypertension. Am J Hypertens 5: 322-324.

4. Oyoo GO, Ogola EN (1999) Clinical and socio demographic aspects of congestive heart failure patients at Kenyatta National Hospital, Nairobi. East Afr Med J 76: 23-27.

5. Bardgett HP, Dixon M, Beeching NJ (2006) Increase in hospital mortality from non-communicable disease and HIV-related conditions in Bulawayo, Zimbabwe, between 1992 and 2000. Trop Doct 36: 129-131.

6. Kingue S, Dzudie A, Menanga A, Akono M, Ouankou M, et al. (2005) [A new look at adult chronic heart failure in Africa in the age of the Doppler echocardiography: experience of the medicine department at Yaounde General Hospital]. Ann Cardiol Angeiol (Paris) 54: 276-283.

7. Khatibzadeh S, Farzadfar F, Oliver J, Ezzati M, Moran A (2013) Worldwide risk factors for heart failure: A systematic review and pooled analysis. Int J Cardiol 168: 1186-1194.

8. Schocken DD, Benjamin EJ, Fonarow GC, Krumholz HM, Levy D, et al. (2008) Prevention of heart failure: a scientific statement from the American Heart Association Councils on Epidemiology and Prevention, Clinical Cardiology, Cardiovascular Nursing, and High Blood Pressure Research; Quality of Care and Outcomes Research Interdisciplinary Working Group; and Functional Genomics and Translational Biology Interdisciplinary Working Group. Circulation 117: 2544-2565

9. Damasceno A, Cotter G, Dzudie A, Sliwa K, Mayosi BM (2007) Heart failure in sub-saharan Africa: time for action. J Am Coll Cardiol 50: 688-693.

10. Owusu IK (2007) Causes of heart failure as seen in Kumasi, Ghana. The Int $J$ Third World Med 5: 1-10.

11. Mendez GF, Cowie MR (2001) The epidemiological features of heart failure in developing countries: a review of the literature. Int J Cardiol 80: 213-219.

12. Yamani M, Massie BM (1993) Congestive heart failure: insights from epidemiology, Implications for treatment. Mayo Clin Proc 68: 1214-1218.

13. American Heart Association (2006) Heart Disease and Stroke Facts, Dallas, Texas

14. Elixhauser A, Yu K, Steiner C, Bierman (1997) Most Common reasons for hospitalizations by age groups, in Hospitalization in the United States, Rockville (Md): Agency for Healthcare Research and Quality, 2000, HCUP Fact Book, AHRQ Publication.

15. Centers for Disease Control and Prevention (1999) The Burden of Heart Disease and Stroke in the United States: State and National Data, Atlanta.

16. Ladipo GO (1981) Congestive cardiac failure in elderly Nigerians: a prospective clinical study. Trop Geogr Med 33: 257-262.

17. Stewart S, Wilkinson D, Becker A, Askew D, Ntyintyane L, et al. (2006) Mapping the emergence of heart disease in a black, urban population in Africa: the Heart of Soweto Study. Int J Cardiol 108: 101-108.

18. Amoah AG, Kallen C (2000) Aetiology of heart failure as seen from a National Cardiac Referral Centre in Africa. Cardiology 93: 11-18.

19. McKee PA, Castelli WP, McNamara PM, Kannel WB (1971) The natural history of congestive heart failure: the Framingham study. N Engl J Med 285: 1441 1446.

20. Chobanian AV, Bakris GL, Black HR, Cushman WC, Green LA, et al. (2003) The seventh report of the Joint National Committee on Prevention, Detection, Evaluation, and Treatment of High Blood Pressure: the JNC 7 report. JAMA 289: 2560-2571.

21. Lemogoum D, Seedat YK, Mabadeje AF, Mendis S, Bovet P, et al. (2003)
Recommendations for prevention, diagnosis and management of hypertension and cardiovascular risk factors in sub-Saharan Africa. J Hypertens 21: 19932000.

22. Beet EA (1956) Rheumatic heart disease in Northern Nigeria. Trans R Soc Trop Med Hyg 50: 587-592.

23. Bukhman G, Kidder A (2008) Cardiovascular disease and global health equity: lessons from tuberculosis control then and now. Am J Public Health 98: 44-54

24. Sliwa K, Mayosi BM (2013) Recent advances in the epidemiology, pathogenesis and prognosis of acute heart failure and cardiomyopathy in Africa. Heart 99: 1317-1322.

25. Bloomfield GS, Barasa FA, Doll JA, Velazquez EJ (2013) Heart failure in subSaharan Africa. Curr Cardiol Rev 9: 157-173.

26. Bahrami H, Kronmal R, Bluemke DA, Olson J, Shea S, et al. (2008) Differences in the incidence of congestive heart failure by ethnicity: the multi-ethnic study of atherosclerosis. Arch Intern Med 168: 2138-2145.

27. Ogah OS, Akinyemi RO, Adegbite GD, Udofia OI, Udoh SB, et al. (2011) Prevalence of asymptomatic left ventricular systolic dysfunction in hypertensive Nigerians: echocardiographic study of 832 subjects. Cardiovasc J Afr 22: 297 302

28. Wang TJ, Evans JC, Benjamin EJ, Levy D, LeRoy EC, et al. (2003) Natura history of asymptomatic left ventricular systolic dysfunction in the community. Circulation 108: 977-982.

29. Luers C, Wachter R, Kleta S, Uhlir M, Koschack J, et al. (2010) Natriuretic peptides in the detection of preclinical diastolic or systolic dysfunction. Clin Res Cardiol 99: 217-226

30. Mayosi BM (2007) Contemporary trends in the epidemiology and management of cardiomyopathy and pericarditis in sub-Saharan Africa. Heart 93: 1176-1183.

31. Cappuccio FP, Micah FB, Emmett L, Kerry SM, Antwi S, et al. (2004) Prevalence, detection, management, and control of hypertension in Ashanti, West Africa. Hypertension 43: 1017-1022.

32. Steyn K, Gaziano TA, Bradshaw D, Laubscher R, Fourie J; South African Demographic and Health Coordinating Team (2001) Hypertension in South African adults: results from the Demographic and Health Survey, 1998. J Hypertens 19: 1717-1725.

33. de Ramirez SS, Enquobahrie DA, Nyadzi G, Mjungu D, Magombo $F$, et al. (2010) Prevalence and correlates of hypertension: a cross-sectional study among rural populations in sub-Saharan Africa. J Hum Hypertens 24: 786-795.

34. Mathenge W, Foster A, Kuper H (2010) Urbanization, ethnicity and cardiovascular risk in a population in transition in Nakuru, Kenya: a populationbased survey. BMC Public Health 10: 569.

35. Anabwani GM, Book W, Bonhoeffer P (1996) Echocardiographic findings in Eldoret: retrospective study. East Afr Med J 73: 714-716.

36. Oli K, Asmera J (2004) Rheumatic heart disease in Ethiopia: could it be more malignant? Ethiop Med J 42: 1-8.

37. Owusu IK, Adu-Boakye, Boadi RK (2013) Cardiovascular Risk Profile of Patients Seen At A Cardiac Clinic In Kumasi, Ghana. The Internet Journal of Health 14: 1

38. Nyenwe EA, Odia OJ, Ihekwaba AE, Ojule A, Babatunde S (2003) Type 2 diabetes in adult Nigerians: a study of its prevalence and risk factors in Port Harcourt, Nigeria. Diabetes Res Clin Pract 62: 177-185.

39. Cooper RS, Amoah AG, Mensah GA (2003) High blood pressure: the foundation for epidemic cardiovascular disease in African populations. Ethn Dis 13: S48-52. 